\title{
Volumetric changes and clinical outcome for petroclival meningiomas after primary treatment with Gamma Knife radiosurgery
}

\author{
Zjiwar H. A. Sadik, MD, ${ }^{1-3}$ Suan Te Lie, MD, ${ }^{1,2}$ Sieger Leenstra, MD, PhD, ${ }^{1,2}$ and \\ Patrick E. J. Hanssens, MD1 \\ ${ }^{1}$ Gamma Knife Center and 2Department of Neurosurgery, Elisabeth-Tweesteden Hospital, Tilburg; and ${ }^{3}$ Department of \\ Neurosurgery, Utrecht University Medical Center, Utrecht, The Netherlands
}

\begin{abstract}
OBJECTIVE Petroclival meningiomas (PCMs) can cause devastating clinical symptoms due to mass effect on cranial nerves (CNs); thus, patients harboring these tumors need treatment. Many neurosurgeons advocate for microsurgery because removal of the tumor can provide relief or result in symptom disappearance. Gamma Knife radiosurgery (GKRS) is often an alternative for surgery because it can cause tumor shrinkage with improvement of symptoms. This study evaluates qualitative volumetric changes of PCM after primary GKRS and its impact on clinical symptoms.
\end{abstract}

METHODS The authors performed a retrospective study of patients with PCM who underwent primary GKRS between 2003 and 2015 at the Gamma Knife Center of the Elisabeth-Tweesteden Hospital in Tilburg, the Netherlands. This study yields 53 patients. In this study the authors concentrate on qualitative volumetric tumor changes, local tumor control rate, and the effect of the treatment on trigeminal neuralgia (TN).

RESULTS Local tumor control was $98 \%$ at 5 years and $93 \%$ at 7 years (Kaplan-Meier estimates). More than $90 \%$ of the tumors showed regression in volume during the first 5 years. The mean volumetric tumor decrease was $21.2 \%, 27.1 \%$, and $31 \%$ at 1,3 , and 6 years of follow-up, respectively. Improvement in TN was achieved in $61 \%, 67 \%$, and $70 \%$ of the cases at 1,2 , and 3 years of follow-up, respectively. This was associated with a mean volumetric tumor decrease of $25 \%$ at the 1-year follow-up to $32 \%$ at the 3-year follow-up.

CONCLUSIONS GKRS for PCMs yields a high tumor control rate with a low incidence of neurological deficits. Many patients with TN due to PCM experienced improvement in TN after radiosurgery. GKRS achieves significant volumetric tumor decrease in the first years of follow-up and thereafter.

https://thejns.org/doi/abs/10.3171/2017.7.JNS17380

KEY WORDS petroclival meningioma; Gamma Knife radiosurgery; volumetric changes; tumor-related trigeminal neuralgia; stereotactic radiosurgery; pain

$\mathrm{M}$ ENINGIOMAS are the second most frequent primary intracranial tumors in adults. Most are benign and account for $33 \%$ of all newly diagnosed brain tumors. ${ }^{11}$ The age-adjusted incidence of meningioma is 7.61/100,000 persons/year. ${ }^{37}$ Meningiomas can occur in different locations within the brain, with $2 \%$ located in the petroclival region. ${ }^{33}$

In a study on petroclival meningiomas (PCMs), the authors reported that, after conservative treatment, $76 \%$ of these tumors grew $(0.81 \mathrm{~mm} / \mathrm{year})$ over a mean follow-up duration of 82 months. ${ }^{55}$ Sixty-three percent of progressive meningiomas were found to induce significant func- tional decline, with $50 \%$ of affected patients developing new cranial nerve $(\mathrm{CN})$ deficits. ${ }^{55}$ This demonstrates that treatment of PCMs with microsurgery, radiosurgery, or radiotherapy is often deemed necessary to prevent clinical worsening.

There is debate regarding treatment options. Many neurosurgeons advocate for microsurgery, since removal of the mass effect (i.e., tumor causing $\mathrm{CN}$ compression) may provide relief or resolution of tumor-related symptoms. However, because of their deep-seated location within the skull base and their association with multiple critical neuronal and vascular structures, it is difficult to

ABBREVIATIONS BNI = Barrow Neurological Institute; $\mathrm{CN}=$ cranial nerve; GKRS = Gamma Knife radiosurgery; PCM = petroclival meningioma; REZ = root exit zone; TN = trigeminal neuralgia; TRTN = tumor-related TN.

SUBMITTED February 12, 2017. ACCEPTED July 24, 2017.

INCLUDE WHEN CITING Published online January 26, 2018; DOI: 10.3171/2017.7.JNS17380. 
achieve total resection. Gross-total removal rates have been reported to range from $20 \%$ to $85 \%$ in the past 25 years. ${ }^{3,4,6,8,29-31,33,34,38,43,47,55,58}$ Despite advances in microsurgery, neuroimaging, and intraoperative neurophysiological monitoring, there is a high rate of complications after surgery. The incidence of $\mathrm{CN}$ deficits after surgery has been reported to range from $28 \%$ to $76 \%$. $3,4,6,8,29-31,33,34,38,43,47,55,58$ Gamma Knife radiosurgery (GKRS) has been increasingly used as a primary treatment for PCMs during the past decade, ${ }^{20,24,26,27,36,44,51,60}$ especially for patients with small tumors $(<3 \mathrm{~cm})$ or elderly patients who may not be able to tolerate surgery due to medical comorbidities. Based on our own experience, GKRS can achieve significant volumetric tumor decrease, resulting in decreased pressure on CNs and symptom improvement. In the present study, we present qualitative volumetric changes after primary GKRS for PCM and relate these to clinical symptoms, in particular trigeminal neuralgia $(\mathrm{TN})$.

\section{Methods \\ Definitions of PCM}

PCMs are defined as meningiomas originating from the upper two-thirds of the clivus with dural attachment centered on the petroclival junction, medial to the internal acoustic meatus, and posterior to the gasserian ganglion. 1,2,7,8,32,51,59 These tumors may have some extension into the cavernous sinus. ${ }^{1}$

\section{Case Selection}

We performed a retrospective analysis of 60 patients who underwent primary GKRS for PCM at the Gamma Knife Center Tilburg between May 2003 and March 2015. We excluded all patients with multiple meningiomas, neurofibromatosis type 2 , and previous intracranial surgery for meningiomas. Our inclusion criteria were follow-up of at least 6 months, incidental meningiomas, and GKRS as primary treatment. This yielded 53 patients for this study.

Hospital records, including clinical notes, doctors' letters, radiology reports, and demographic data, were reviewed, and data were extracted for analysis. Pre- and post-GKRS clinical characteristics were reviewed. In this study we concentrate on qualitative volumetric tumor changes, local tumor control rate, and effect of the treatment on TN.

\section{Volumetric Measurement}

Tumor progression after GKRS was defined as a greater than $10 \%$ increase in tumor volume compared with the volume at the time of radiosurgery. This is based on a volumetric algorithm that demonstrated that on postradiosurgery imaging, tumors should be considered unchanged when the volume difference is less than $10 \%$. $^{46}$

All measurements on images were obtained twice. Two physicians (a resident and a neurosurgeon) experienced in brain imaging independently performed volumetric measurements for all patients on the contrast-enhanced T1weighted images, which were imported into the Leksell GammaPlan software (Elekta AB). The MR images used for follow-up had a slice thickness of $1.5 \mathrm{~mm}$. This was consistent for all patients throughout follow-up.
All available MR images were imported into Leksell GammaPlan for volumetric calculation of the tumor before GKRS and during follow-up. The interobserver variability was no more than the $10 \%$ cutoff point.

\section{Pain Score}

Trigeminal neuralgia was defined as facial pain and was scored according to the Barrow Neurological Institute (BNI) pain intensity scoring. ${ }^{39}$

Complete pain resolution was defined as pain free without medication (BNI score I). Pain improvement was defined as any improvement in the BNI score compared with the initial BNI score. ${ }^{14}$ Pain recurrence was defined as any worsening in pain after initial improvement during follow-up..$^{14} \mathrm{TN}$ type ${ }^{19,54}$ was also evaluated. All patients with facial pain had type $1 \mathrm{TN}$, which is typically sharp, shooting, electrical shock-like, with pain-free intervals between the attacks.

\section{Pretreatment Patient Characteristics}

The median age at the time of GKRS was 56 years (range 33-90 years). Of the 53 patients (7 male and 46 female), 14 (26\%) had cavernous sinus involvement. Twentythree (43\%) patients had type $1 \mathrm{TN}$ (Table 1).

\section{GKRS Procedure}

The GKRS procedure was performed using a Leksell Gamma Knife 4C model, before 2009, and a Leksell Gam-

\section{TABLE 1. Pretreatment characteristics}

\begin{tabular}{lc}
\hline \multicolumn{1}{c}{ Characteristic } & Value \\
\hline Male/female ratio & $7: 46$ \\
\hline Age at time of GKRS in yrs & $57.8 \pm 12.7$ \\
\hline Mean \pm SD & $56(33-90)$ \\
\hline Median (range) & \\
\hline Treatment vol in cm ${ }^{3}$ & $4.0 \pm 3.2$ \\
\hline Mean \pm SD & $3.1(0.13-11.4)$ \\
\hline Median (range) & \\
\hline Length of follow-up in mos & $64.2 \pm 33.7$ \\
\hline Mean \pm SD & $59.0(12-147)$ \\
\hline Median (range) & $39(74)$ \\
\hline No. w/o cavernous sinus involvement & $14(26)$ \\
\hline No. w/ cavernous sinus involvement & $30(57)$ \\
\hline Trigeminal pain score at GKRS & $3(6)$ \\
\hline BNI score I & $4(8)$ \\
\hline BNI score II & $15(28)$ \\
\hline BNI score III & $1(2)$ \\
\hline BNI score IV & $23(43)$ \\
\hline BNI score V & 0 \\
\hline Type of trigeminal pain & \\
\hline Type 1 & \\
\hline Type 2 & \\
\hline
\end{tabular}

Values are presented as the number of patients (\%) unless stated otherwise. Mean values are presented as the mean \pm SD. Median values are presented as the median (range). 


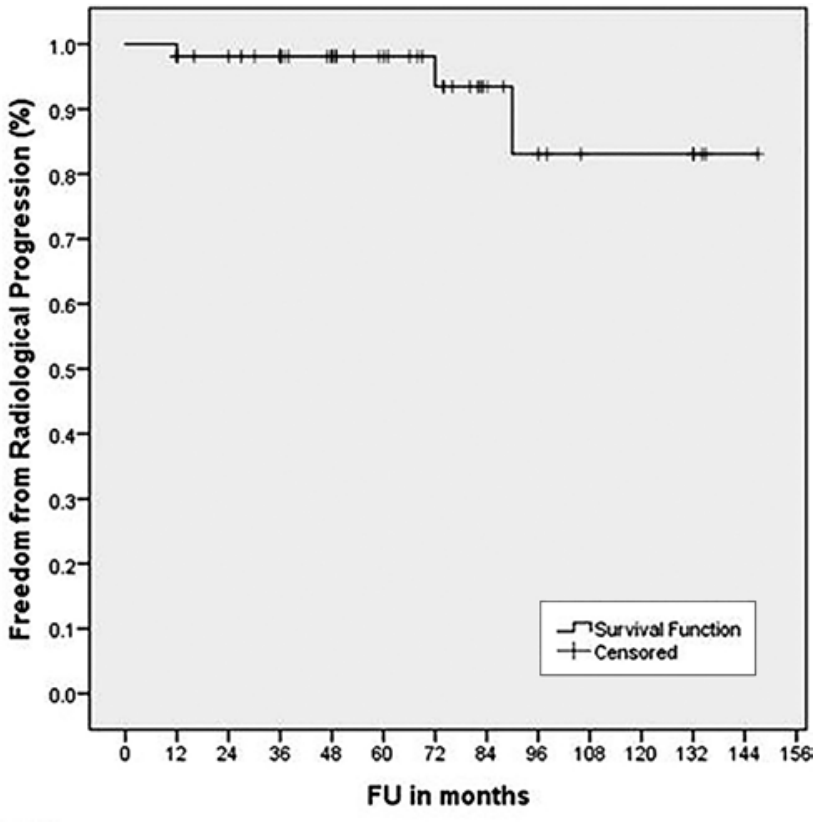

No. of patients

$\begin{array}{llllllll}50 & 46 & 37 & 30 & 19 & 14 & 10\end{array}$

5

FIG. 1. Kaplan-Meier analysis of radiological tumor control. FU = follow-up.

ma Knife Perfexion (Elekta AB) thereafter. Leksell GammaPlan was used for treatment planning. The application of the Leksell G-frame was performed in the patient's room after application of a local anesthetic solution. Following frame placement, high-resolution stereotactic MRI was performed for treatment planning. Precontrast and postcontrast (15-mg intravenous Gd) T1-weighted axial images were obtained with a slice thickness of $1.5 \mathrm{~mm}$. Dose planning was performed by a neurosurgeon, radiation oncologist, and medical physicist. The target was defined as the contrast-enhancing lesion on the planning MR image. The mean tumor volume was $4.00 \mathrm{~cm}^{3}$ (range $0.13-11.35 \mathrm{~cm}^{3}$ ). The median prescribed dose was 13 Gy (range 11-15 Gy) to that isodose covering $90 \%-100 \%$ of the target.

During the treatment planning, $\mathrm{CN} \mathrm{V}$ was not visible due to the tumor mass, making it impossible to determine the proximity of the trigeminal nerve to the tumor. This was the case for all patients.

\section{Statistical Analysis}

All statistical analyses were performed using IBM SPSS statistics version 23. A Kaplan-Meier curve was

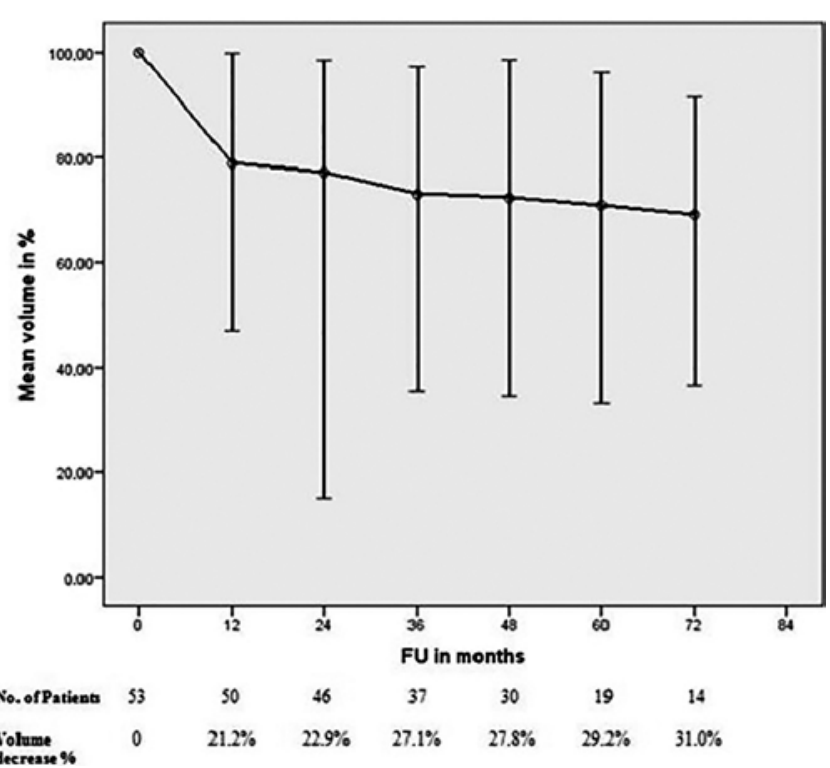

FIG. 2. Volumetric tumor decrease during follow-up with whisker plots of standard error of the mean.

plotted. A scatter plot was plotted to determine the volumetric change during follow-up.

\section{Results}

\section{Tumor Control}

The median follow-up duration was 59 months (range 12-147 months). Radiological tumor control was $98 \%$ at the 5-year and $93 \%$ at the 7-year follow-up time points (Fig. 1). More than $90 \%$ of the tumors showed regression of tumor volume during the first 5 years of follow-up (Table 2). After GKRS, the mean volumetric tumor decreases at $1,2,3,4,5$, and 6 years of follow-up were $21.2 \%$ (range $0.1 \%-53.1 \%$ ), $22.9 \%$ (range $1.5 \%-84.9 \%$ ), $27.1 \%$ (range $2.7 \%-64.6 \%$ ), $27.8 \%$ (range 1.4\%-65.5\%), 29.2\% (range $3.8 \%-66.9 \%$ ), and $31 \%$ (range $8.5 \%-63.5 \%$ ), respectively (Fig. 2).

\section{Trigeminal Neuralgia}

Patients who did not have TN prior to GKRS did not develop TN after radiosurgery. The pain recurrence rate was $26 \%$ (5 of 19 patients). The mean follow-up duration until pain recurrence was 16.7 months (range 12-24 months). Those with BNI score $\geq$ II showed an improvement at 1,2 , and 3 years of $61 \%, 67 \%$, and $70 \%$, respectively (Table 3 ). These patients showed a mean volumetric

TABLE 2. Volumetric changes of tumor during follow-up according to the $10 \%$ cutoff point

\begin{tabular}{lcccccccc}
\hline & \multicolumn{7}{c}{ Follow-Up in Yrs } \\
\cline { 2 - 9 } Tumor Behavior & $1(\mathrm{n}=50)$ & $2(\mathrm{n}=46)$ & $3(\mathrm{n}=37)$ & $4(\mathrm{n}=30)$ & $5(\mathrm{n}=19)$ & $6(\mathrm{n}=14)$ & $7(\mathrm{n}=10)$ & Last $(\mathrm{n}=53)$ \\
\hline Regression & $46(92)$ & $43(93)$ & $36(97)$ & $30(100)$ & $19(100)$ & $12(86)$ & $9(90)$ & $49(92)$ \\
\hline Stable & $3(6)$ & $1(2)$ & $1(3)$ & 0 & 0 & $1(7)$ & $1(10)$ & $3(6)$ \\
\hline Progression & $1(2)$ & $2(4)$ & 0 & 0 & 0 & $1(7)$ & 0 & $1(2)$ \\
\hline
\end{tabular}

Values are presented as the number of patients (\%). 
TABLE 3. Evolution of TN and mean volume change during follow-up

\begin{tabular}{|c|c|c|c|c|c|c|c|c|c|c|}
\hline \multirow[b]{2}{*}{ TN Status } & \multicolumn{2}{|c|}{$1 \mathrm{Yr}(\mathrm{n}=23)$} & \multicolumn{2}{|c|}{$2 \operatorname{Yr}(n=21)$} & \multicolumn{2}{|c|}{$3 \operatorname{Yr}(n=20)$} & \multicolumn{2}{|c|}{$5 \operatorname{Yr}(n=11)$} & \multicolumn{2}{|c|}{$7 \operatorname{Yr}(n=3)$} \\
\hline & No. of Pts (\%) & MVC & No. of Pts $(\%)$ & MVC & No. of Pts (\%) & MVC & No. of Pts (\%) & MVC & No. of Pts (\%) & MVC \\
\hline Improved & $14(61)$ & $-25.2 \%$ & $14(67)$ & $-26.8 \%$ & $14(70)$ & $-31.8 \%$ & $7(64)$ & $-24.6 \%$ & $1(33)$ & NA \\
\hline Stable & $8(35)$ & $-16.6 \%$ & $5(24)$ & $-40.3 \%$ & $5(25)$ & $-16.0 \%$ & $4(36)$ & $-35.4 \%$ & $1(33)$ & $6.0 \%$ \\
\hline Deteriorated & $1(4)$ & $15.2 \%$ & $2(9)$ & $6.0 \%$ & $1(5)$ & $8.4 \%$ & 0 & 0 & $1(33)$ & $-21.3 \%$ \\
\hline
\end{tabular}

$\mathrm{MVC}=$ mean volume change $; \mathrm{NA}=$ not available; pts $=$ patients

tumor decrease of $25 \%-32 \%$. None of the patients with BNI score II improved to BNI score I. Only one of the 4 patients with BNI score III improved to BNI score I at the 1-year follow-up and remained at BNI score I during the 5-year follow-up. Five patients (33\%) improved from a BNI score of IV to I during the first 3 years of follow-up. Complete pain resolution was achieved for patients with BNI score $\geq$ II in $21 \%, 33 \%$, and $33 \%$ of the cases at the $1-, 2-$, and 3-year follow-ups, respectively. TN remained stable in $35 \%$ of the cases at the 1-year follow-up to $25 \%$ at the 3-year follow-up. However, these patients also exhibited a volumetric tumor decrease (Table 3). In total, 23 patients had TN (BNI score $\geq$ II).

\section{Complications}

Complications occurred in 3 patients (5\%). One patient experienced transient worsening of trigeminal nerve function within the first 24 months of treatment and recovered within a few weeks of receiving dexamethasone. This patient had transient volumetric tumor enlargement. Another patient continued having severe pain after GKRS requiring extra analgesics; this patient eventually underwent surgery, which resulted in complete pain resolution thereafter. This patient had no volumetric tumor enlargement. In the third patient, complications were related to CN VIII (transient deterioration of balance difficulties). No newonset radiological changes were observed in the brainstem on follow-up MRI, and no delayed-onset hydrocephalus was reported.

\section{Discussion}

GKRS resulted in a good tumor control rate of $98 \%$ at 5 years and a $93 \%$ at 7 years. This is within the range of other studies that have reported a tumor control rate of $87 \%-98 \%$ for skull base meningioma treated with primary GKRS. ${ }^{13,36,45,50,51}$ Our data and those of others confirm that in smaller meningiomas, radiosurgery can generally provide results similar to those of a Simpson grade I resection. ${ }^{41}$

The measurement method and the definition of tumor progression are relevant, since some neurosurgeons consider undeniable radiological progression a treatment failure and an indication for further treatment, mostly excision. Consensus, however, is lacking on the measurement method, cutoff value, and interpretation of possible tumor enlargement, whether it is due to measurement errors, transient reactive swelling, or tumor growth. In all previous studies on PCMs, 2D measurement or maximum diameter/linear measurement was used to determine tumor growth.
Diameter measurement is more than twice as inaccurate as volume measurement. ${ }^{57}$ A $5-\mathrm{mm}$ tumor would have to grow 2.8 times its original volume for growth to be confidently detected with use of maximum diameter measurement. ${ }^{56}$ This also applies to 2D measurements, whereby a $10 \%$ increase results in $30 \%$ volume increase. Therefore, small changes in smaller tumors are difficult to detect with maximum diameter measurement or $2 \mathrm{D}$ measurement. Three-dimensional volumetric measurement should therefore always be used for accurate detection of tumor response after radiosurgery. This is the first study reporting on qualitative volumetric changes during follow-up after primary GKRS for PCM. To the best of our knowledge, only 4 other studies have demonstrated volume decrease for posterior fossa meningioma after GKRS. Sheehan et al. demonstrated a mean volumetric decrease of $25 \%$ at a follow-up time of 5 years. ${ }^{45}$ Starke et al. showed a mean volumetric decrease of only $14 \%$ at a median follow-up time of 7 years. ${ }^{50}$ However, in 2014 the authors demonstrated a mean volumetric decrease of $21 \%$ at the last follow-up. ${ }^{49}$ The most recent study about volumetric response showed a $20 \%$ volume reduction at a median follow-up of 28 months. ${ }^{15}$

A possible explanation for these differences compared with our study is that a large portion of these study populations had undergone prior treatment, either surgery $(43 \%-51 \%)^{15,45,49,50}$ or radiotherapy $(1.2 \%-1.6 \%),{ }^{45,49}$ or a combination of both. Location of the meningioma is another important aspect for explaining the difference in volumetric reduction. Three of the 4 studies included meningiomas that were located in different locations within the brain. $15,45,50$

In our study, primary GKRS led to a mean volumetric decrease of $21 \%$ in the 1st year after treatment. Thereafter, the decrease was less steep, eventually reaching a mean volumetric decrease of $31 \%$ at 6 years of follow-up (Fig. 2). This demonstrates that GKRS can achieve significant volumetric tumor decrease immediately in the 1st year of follow-up, thereby reducing the mass effect of the tumor on CNs.

Many patients with PCM experience TN, also known as tumor-related TN (TRTN). TRTN is a neuralgic pain caused by a tumor attached to components of $\mathrm{CN}$ V. The goal of treatment of TRTN is tumor control and relief of neurological pain. In the mid-1990s, treatment of TRTN with GKRS was done for the first time in a relatively small group of patients and resulted in a rapid clinical improvement. ${ }^{42}$ In this series, we have demonstrated an improvement in $\mathrm{TN}$ in $61 \%$ of the patients at 1 year and in $70 \%$ at the 3-year follow-up. Overall, TN was stable or improved in $96 \%, 91 \%$, and $95 \%$ of the patients at 1,2 , and 3 years, 
respectively (Table 3). Complete pain resolution was achieved for patients with BNI score $\geq$ II in $21 \%, 33 \%$, and $33 \%$ of the cases at the 1-, 2-, and 3-year follow-ups, respectively. This rate of complete pain resolution without any medication is comparable to those of previous studies of radiosurgery targeting the tumor alone, in which complete pain resolution of $33 \%-58 \%$ was reported. ${ }^{17,22,40,48,54}$ The pain recurrence rate in our study was $26 \%$. This rate has been reported to range from $24 \%$ to $47 \%$ in TRTN patients after radiosurgery targeting only the mass lesion. ${ }^{17,22,40,48,54}$ A possible explanation for the low rate of complete pain resolution when only targeting the tumor is that the blood vessel that is displaced by the tumor can be located near the trigeminal root exit zone (REZ), thus acting like an offending vessel, similar to the etiology of idiopathic TN..$^{5,21,53}$ The relationship between volumetric tumor reduction and pain control is disputed, because initial pain response is reported to precede tumor shrinkage in patients with TRTN after radiosurgery. ${ }^{17}$ However, Huang et al. reported that the only significant factor for complete pain relief was tumor volume shrinkage $(\mathrm{p}=$ 0.0495). ${ }^{17}$ A possible explanation of pain relief preceding tumor shrinkage may be due to radiosurgery-induced blockage of demyelination of the nerve root. $^{25}$

Kano et al. and Tanaka et al. reported that tumor shrinkage was not associated with pain relief. ${ }^{22,54}$ In these 2 studies, changes in tumor mass during follow-up were determined through maximum linear measurement and not with 3D measurement. Almost all tumors decreased or remained stable after GKRS. Because this type of measurement is less accurate than 3D measurement, one can postulate that if 3D measurements had been obtained, shrinkage of almost all tumors could have been possible, therefore possibly altering the conclusion.

In our study, the majority of the patients whose $\mathrm{TN}$ was stable or improved showed a decrease in tumor volume (Table 3). However, this retrospective study does not permit conclusions about causality.

Because of the low rate of complete pain resolution and unclear association of pain relief and tumor shrinkage, we should look at possibilities to increase pain relief in TRTN patients. A way to achieve this is by targeting both the tumor and the trigeminal REZ in a single session. This method was demonstrated by Kim et al., who reported a pain recurrence rate of $21.4 \%,{ }^{23}$ which was better than that previously reported $(24 \%-47 \%)$. $^{17,22,40,48,54}$ Their complete pain resolution was $66.7 \%,{ }^{23}$ which was also better than that previously reported $(33 \%-58 \%))^{17,22,40,48,54}$ The complication rate in their study was $20 \%$ (persistent new facial numbness). ${ }^{23}$

This method, targeting both the tumor and trigeminal REZ in 1 session, might be considered primary treatment in the future for TRTN patients in our center because of the high rate of complete pain resolution. In TRTN patients, the REZ or the trigeminal nerve is not always recognizable due to the tumor, and therefore it is not always possible to target it with GKRS. In that case, an alternative is to target the trigeminal nerve more distally on the petrosal bone.

In the current study, complications occurred in 3 patients (5\%). In 1 patient, the complications were related to CN VIII (transient deterioration of balance difficulties). Long-term postradiosurgical complications (any $\mathrm{CN}$ dysfunction and neurological deficit) are reported to range between $0 \%$ and $16 \%$ in centers using median doses of $12-15$ Gy. ${ }^{9}, 10,12,16,18,24,26-28,35,52$

\section{Study Limitations}

This study is a single-center retrospective study and therefore is subjected to biases (selection bias and treatment bias) and limitations. The lack of an untreated control group limits our ability to assess the full benefit of GKRS. Our sample size was relatively small and throughout follow-up we have lost patients, either because follow-up occurred at another hospital or because patients refused it. In some patients the MRI studies could not be imported into the GammaPlan because they were not DICOM files and were nonsquare pixels/voxels. The median follow-up time was 5 years, and we may have incompletely assessed longterm clinical outcome such as TN and volumetric tumor decrease. The TRTN patients were treated with primary GKRS, and therefore the tumors could not be histologically confirmed to be meningiomas, but rather were diagnosed based on radiological features. Thus, it is possible that other benign tumors were included in this study and therefore influenced its outcome.

\section{Conclusions}

GKRS for PCMs yields a high tumor control rate with a low incidence of neurological deficits. Many patients with TN due to PCM experienced improvement in TN after radiosurgery. GKRS achieves significant volumetric tumor decrease in the first years of follow-up and thereafter.

\section{References}

1. Al-Mefty O: Operative Atlas of Meningiomas. Philadelphia: Lippincott-Raven, 1998

2. Al-Mefty O, Fox JL, Smith RR: Petrosal approach for petroclival meningiomas. Neurosurgery 22:510-517, 1988

3. Almefty R, Dunn IF, Pravdenkova S, Abolfotoh M, Al-Mefty $O$ : True petroclival meningiomas: results of surgical management. J Neurosurg 120:40-51, 2014

4. Bambakidis NC, Kakarla UK, Kim LJ, Nakaji P, Porter RW, Daspit CP, et al: Evolution of surgical approaches in the treatment of petroclival meningiomas: a retrospective review. Neurosurgery 61 (5 Suppl 2):202-211, 2007

5. Barker FG II, Jannetta PJ, Babu RP, Pomonis S, Bissonette DJ, Jho HD: Long-term outcome after operation for trigeminal neuralgia in patients with posterior fossa tumors. J Neurosurg 84:818-825, 1996

6. Bricolo AP, Turazzi S, Talacchi A, Cristofori L: Microsurgical removal of petroclival meningiomas: a report of 33 patients. Neurosurgery 31:813-828, 1992

7. Castellano F, Ruggiero G: Meningiomas of the posterior fossa. Acta Radiol Suppl 104:1-177, 1953

8. Couldwell WT, Fukushima T, Giannotta SL, Weiss MH: Petroclival meningiomas: surgical experience in 109 cases. $\mathbf{J}$ Neurosurg 84:20-28, 1996

9. DiBiase SJ, Kwok Y, Yovino S, Arena C, Naqvi S, Temple $\mathrm{R}$, et al: Factors predicting local tumor control after gamma knife stereotactic radiosurgery for benign intracranial meningiomas. Int J Radiat Oncol Biol Phys 60:1515-1519, 2004 
10. Eustacchio S, Trummer M, Fuchs I, Schröttner O, Sutter B, Pendl G: Preservation of cranial nerve function following Gamma Knife radiosurgery for benign skull base meningiomas: experience in 121 patients with follow-up of 5 to 9.8 years. Acta Neurochir Suppl 84:71-76, 2002

11. Fathi AR, Roelcke U: Meningioma. Curr Neurol Neurosci Rep 13:337, 2013

12. Feigl GC, Samii M, Horstmann GA: Volumetric follow-up of meningiomas: a quantitative method to evaluate treatment outcome of gamma knife radiosurgery. Neurosurgery 61:281-287, 2007

13. Flannery TJ, Kano H, Lunsford LD, Sirin S, Tormenti M, Niranjan A, et al: Long-term control of petroclival meningiomas through radiosurgery. J Neurosurg 112:957-964, 2010

14. Han JH, Kim DG, Chung HT, Paek SH, Kim YH, Kim CY, et al: Long-term outcome of gamma knife radiosurgery for treatment of typical trigeminal neuralgia. Int J Radiat Oncol Biol Phys 75:822-827, 2009

15. Harrison G, Kano H, Lunsford LD, Flickinger JC, Kondziolka D: Quantitative tumor volumetric responses after Gamma Knife radiosurgery for meningiomas. J Neurosurg 124:146154,2016

16. Hasegawa T, Kida Y, Yoshimoto M, Koike J, Iizuka H, Ishii D: Long-term outcomes of Gamma Knife surgery for cavernous sinus meningioma. J Neurosurg 107:745-751, 2007

17. Huang CF, Tu HT, Liu WS, Lin LY: Gamma Knife surgery for trigeminal pain caused by benign brain tumors. J Neurosurg 109 Suppl:154-159, 2008

18. Hudgins WR, Barker JL, Schwartz DE, Nichols TD: Gamma Knife treatment of 100 consecutive meningiomas. Stereotact Funct Neurosurg 66 (Suppl 1):121-128, 1996

19. International Headache Society: The International Classification of Headache Disorders: 3rd edition (beta version). Cephalalgia 33:629-808, 2013

20. Iwai Y, Yamanaka K, Nakajima H: Two-staged Gamma Knife radiosurgery for the treatment of large petroclival and cavernous sinus meningiomas. Surg Neurol 56:308-314, 2001

21. Jannetta PJ: Treatment of trigeminal neuralgia by suboccipital and transtentorial cranial operations. Clin Neurosurg 24:538-549, 1977

22. Kano H, Awan NR, Flannery TJ, Iyer A, Flickinger JC, Lunsford $\mathrm{LD}$, et al: Stereotactic radiosurgery for patients with trigeminal neuralgia associated with petroclival meningiomas. Stereotact Funct Neurosurg 89:17-24, 2011

23. Kim SK, Kim DG, Se YB, Kim JW, Kim YH, Chung HT, et al: Gamma Knife surgery for tumor-related trigeminal neuralgia: targeting both the tumor and the trigeminal root exit zone in a single session. J Neurosurg 125:838-844, 2016

24. Kollová A, Liscák R, Novotný J Jr, Vladyka V, Simonová G, Janousková L: Gamma Knife surgery for benign meningioma. J Neurosurg 107:325-336, 2007

25. Kondziolka D, Lacomis D, Niranjan A, Mori Y, Maesawa $\mathrm{S}$, Fellows W, et al: Histological effects of trigeminal nerve radiosurgery in a primate model: implications for trigeminal neuralgia radiosurgery. Neurosurgery 46:971-977, 2000

26. Kondziolka D, Mathieu D, Lunsford LD, Martin JJ, Madhok R, Niranjan A, et al: Radiosurgery as definitive management of intracranial meningiomas. Neurosurgery 62:53-60, 2008

27. Kreil W, Luggin J, Fuchs I, Weigl V, Eustacchio S, Papaefthymiou $\mathrm{G}$ : Long term experience of gamma knife radiosurgery for benign skull base meningiomas. J Neurol Neurosurg Psychiatry 76:1425-1430, 2005

28. Lee JY, Niranjan A, McInerney J, Kondziolka D, Flickinger JC, Lunsford LD: Stereotactic radiosurgery providing longterm tumor control of cavernous sinus meningiomas. J Neurosurg 97:65-72, 2002

29. Li D, Hao SY, Wang L, Tang J, Xiao XR, Zhou H, et al: Surgical management and outcomes of petroclival meningiomas: a single-center case series of 259 patients. Acta Neurochir (Wien) 155:1367-1383, 2013

30. Li D, Tang J, Ren C, Wu Z, Zhang LW, Zhang JT: Surgical management of medium and large petroclival meningiomas: a single institution's experience of 199 cases with long-term follow-up. Acta Neurochir (Wien) 158:409-425, 2016

31. Little KM, Friedman AH, Sampson JH, Wanibuchi M, Fukushima T: Surgical management of petroclival meningiomas: defining resection goals based on risk of neurological morbidity and tumor recurrence rates in 137 patients. Neurosurgery 56:546-559, 2005

32. Mayberg MR, Symon L: Meningiomas of the clivus and apical petrous bone. Report of 35 cases. J Neurosurg 65:160167,1986

33. Nanda A, Javalkar V, Banerjee AD: Petroclival meningiomas: study on outcomes, complications and recurrence rates. J Neurosurg 114:1268-1277, 2011

34. Natarajan SK, Sekhar LN, Schessel D, Morita A: Petroclival meningiomas: multimodality treatment and outcomes at long-term follow-up. Neurosurgery 60:965-981, 2007

35. Nicolato A, Foroni R, Alessandrini F, Maluta S, Bricolo A, Gerosa M: The role of Gamma Knife radiosurgery in the management of cavernous sinus meningiomas. Int J Radiat Oncol Biol Phys 53:992-1000, 2002

36. Nicolato A, Foroni R, Pellegrino M, Ferraresi P, Alessandrini $\mathrm{F}$, Gerosa $\mathrm{M}$, et al: Gamma knife radiosurgery in meningiomas of the posterior fossa. Experience with 62 treated lesions. Minim Invasive Neurosurg 44:211-217, 2001

37. Ostrom QT, Gittleman H, Liao P, Rouse C, Chen Y, Dowling $\mathrm{J}$, et al: CBTRUS statistical report: primary brain and central nervous system tumors diagnosed in the United States in 2007-2011. Neuro Oncol 16 (Suppl 4):iv1-iv63, 2014

38. Park CK, Jung HW, Kim JE, Paek SH, Kim DG: The selection of the optimal therapeutic strategy for petroclival meningiomas. Surg Neurol 66:160-166, 2006

39. Pollock BE: Contemporary Stereotactic Radiosurgery: Technique and Evaluation. Armonk, NY: Futura Publishing Company, 2002

40. Pollock BE, Iuliano BA, Foote RL, Gorman DA: Stereotactic radiosurgery for tumor-related trigeminal pain. Neurosurgery 46:576-583, 2000

41. Pollock BE, Stafford SL, Utter A, Giannini C, Schreiner SA: Stereotactic radiosurgery provides equivalent tumor control to Simpson Grade 1 resection for patients with small- to medium-size meningiomas. Int J Radiat Oncol Biol Phys 55:1000-1005, 2003

42. Régis J, Manera L, Dufour H, Porcheron D, Sedan R, Peragut JC: Effect of the Gamma Knife on trigeminal neuralgia. Stereotact Funct Neurosurg 64 (Suppl 1):182-192, 1995

43. Roberti F, Sekhar LN, Kalavakonda C, Wright DC: Posterior fossa meningiomas: surgical experience in 161 cases. Surg Neurol 56:8-21, 2001

44. Roche PH, Pellet W, Fuentes S, Thomassin JM, Régis J: Gamma knife radiosurgical management of petroclival meningiomas results and indications. Acta Neurochir (Wien) 145:883-888, 2003

45. Sheehan JP, Starke RM, Kano H, Barnett GH, Mathieu D, Chiang V, et al: Gamma Knife radiosurgery for posterior fossa meningiomas: a multicenter study. J Neurosurg 122:1479-1489, 2015

46. Snell JW, Sheehan J, Stroila M, Steiner L: Assessment of imaging studies used with radiosurgery: a volumetric algorithm and an estimation of its error. Technical note. J Neurosurg 104:157-162, 2006

47. Spetzler RF, Daspit CP, Pappas CT: The combined supra- and infratentorial approach for lesions of the petrous and clival regions: experience with 46 cases. J Neurosurg 76:588-599, 1992

48. Squire SE, Chan MD, Furr RM, Lowell DA, Tatter SB, El- 
lis TL, et al: Gamma knife radiosurgery in the treatment of tumor-related facial pain. Stereotact Funct Neurosurg 90:145-150, 2012

49. Starke R, Kano H, Ding D, Nakaji P, Barnett GH, Mathieu D, et al: Stereotactic radiosurgery of petroclival meningiomas: a multicenter study. J Neurooncol 119:169-176, 2014

50. Starke RM, Nguyen JH, Rainey J, Williams BJ, Sherman JH, Savage J, et al: Gamma Knife surgery of meningiomas located in the posterior fossa: factors predictive of outcome and remission. J Neurosurg 114:1399-1409, 2011

51. Subach BR, Lunsford LD, Kondziolka D, Maitz AH, Flickinger JC: Management of petroclival meningiomas by stereotactic radiosurgery. Neurosurgery 42:437-445, 1998

52. Takanashi M, Fukuoka S, Hojyo A, Sasaki T, Nakagawara J, Nakamura H: Gamma knife radiosurgery for skull-base meningiomas. Prog Neurol Surg 22:96-111, 2009

53. Tan LA, Gerard CS, Ahuja SK, Moftakhar R: Retrosigmoid approach for resection of cerebellopontine angle meningioma and decompression of the trigeminal nerve. Neurosurg Focus 36 (1 Suppl):1, 2014

54. Tanaka S, Pollock BE, Stafford SL, Link MJ: Stereotactic radiosurgery for trigeminal pain secondary to benign skull base tumors. World Neurosurg 80:371-377, 2013

55. Van Havenbergh T, Carvalho G, Tatagiba M, Plets C, Samii M: Natural history of petroclival meningiomas. Neurosurgery 52:55-64, 2003

56. Vokurka EA, Herwadkar A, Thacker NA, Ramsden RT, Jackson A: Using Bayesian tissue classification to improve the accuracy of vestibular schwannoma volume and growth measurement. AJNR Am J Neuroradiol 23:459-467, 2002

57. Walz PC, Bush ML, Robinett Z, Kirsch CF, Welling DB: Three-dimensional segmented volumetric analysis of sporadic vestibular schwannomas: comparison of segmented and linear measurements. Otolaryngol Head Neck Surg 147:737-743, 2012

58. Yang J, Fang T, Ma S, Yang S, Qi J, Qi Z, et al: Large and giant petroclival meningiomas: therapeutic strategy and the choice of microsurgical approaches - report of the experience with 41 cases. Br J Neurosurg 25:78-85, 2011
59. Yaşargil MG, Mortara RW, Curcic M: Meningiomas of basal posterior cranial fossa, in Krayenbühl H (ed): Advances and Technical Standards in Neurosurgery. New York: Springer, 1980, Vol 7

60. Zachenhofer I, Wolfsberger S, Aichholzer M, Bertalanffy A, Roessler K, Kitz K, et al: Gamma-knife radiosurgery for cranial base meningiomas: experience of tumor control, clinical course, and morbidity in a follow-up of more than 8 years. Neurosurgery 58:28-36, 2006

\section{Disclosures}

The authors report no conflict of interest concerning the materials or methods used in this study or the findings specified in this paper.

\section{Author Contributions}

Conception and design: all authors. Acquisition of data: Sadik, Lie. Analysis and interpretation of data: Sadik, Leenstra, Hanssens. Drafting the article: Sadik. Critically revising the article: Lie, Leenstra, Hanssens. Approved the final version of the manuscript on behalf of all authors: Sadik. Statistical analysis: Sadik. Administrative/technical/material support: Sadik, Lie. Study supervision: Sadik, Hanssens.

\section{Supplemental Information \\ Previous Presentations}

Portions of this work were presented as an oral presentation at the 18th Leksell Gamma Knife Society Meeting, Amsterdam, the Netherlands, May 15-19, 2016.

\section{Correspondence}

Zjiwar H. A. Sadik: Elisabeth-Tweesteden Hospital, Tilburg, The Netherlands.z.sadik@etz.nl. 